\title{
Accounting for Heterogeneous Variances in Multitrait Evaluation of Jersey Type Traits
}

\author{
N. Gengler, ${ }^{*} \dagger$ G. R. Wiggans, $\neq^{1}$ L. L. M. Thornton, $\neq$ J. R. Wright, $\neq$ and T. Druet ${ }^{\star} \dagger^{2}$ \\ ${ }^{*}$ National Fund for Scientific Research, B-1000 Brussels, Belgium \\ †Animal Science Unit, Gembloux Agricultural University, B-5030 Gembloux, Belgium \\ ‡Animal Improvement Programs Laboratory, Agricultural Research Service, USDA, Beltsville, MD 20705-2350
}

\section{ABSTRACT}

The multitrait genetic evaluation system for type traits was modified to estimate adjustments for heterogeneous variance (HV) simultaneously with estimated breeding values (EBV) for final score and 14 linear traits. Each variance within herd, year, and parity was regressed toward a predicted variance, which was determined by fitting a model with fixed effects of the mean final score for herd, size of the contemporary group, appraisal month, and year-season and a random effect for herd-appraisal date. Herd-appraisal date was included as a random effect to regress the observed heterogeneity for a given herd-appraisal date toward the fixed effects. Method $\mathrm{R}$ was used to estimate variances for the heterogeneity model in each EBV iteration. To evaluate the effect of the adjustment, parent averages were calculated from evaluations with recent appraisals removed. The adjustment slightly improved correlations within birth year between those parent averages and EBV from current data on bulls for most traits, but did not improve correlations for final score, strength, dairy form, teat length, or foot angle. Annual trends for EBV were lower with $\mathrm{HV}$ adjustment than for unadjusted EBV for all traits except final score and rump angle for cows and rump width for bulls, which were essentially unchanged. Standard deviations of Mendelian sampling (evaluation minus mean of parent evaluations) declined less over time for $\mathrm{HV}$-adjusted than for unadjusted evaluations. The slope at year 2000 of Mendelian-sampling standard deviations from HVadjusted evaluations ranged from $10.0 \%$ for udder depth to $42.7 \%$ for teat length compared with the slope for unadjusted evaluations. This HV adjustment, which was implemented for USDA evaluations in May 2001 for Jerseys and in 2002 for other breeds, improves the

Received December 28, 2005.

Accepted February 13, 2006.

${ }^{1}$ Corresponding author: wiggans@aipl.arsusda.gov

${ }^{2}$ Current address: Station de Génétique Quantitative et Appliquée, INRA, Jouy-en-Josas 78352, France. accuracy of evaluations, particularly comparisons over time, by accounting for the change in variation.

Key words: heterogeneous variance adjustment, type evaluation

\section{INTRODUCTION}

A multitrait animal model (Gengler et al., 1997a, 1997b, 1999) has been used to calculate type evaluations for the Jersey breed since February 1998. In that analysis, homogeneity of (co)variances is assumed. Weigel and Lawlor (1994) found that variance decreased as the average final score of a herd increased. This finding explained the results of Bell et al. (1982) that bull evaluations for type differed among groups stratified by herd average final score. Gengler et al. (2001) found that variances were heterogeneous for all type traits. This heterogeneity should be accounted for in routine genetic evaluations.

Data can be adjusted to stabilize variances by contemporary group before evaluation. This strategy is used for the Holstein final score. Weigel and Lawlor (1994) described a method of adjustment for heterogeneous variance $(\mathbf{H V})$ that included predicting variance from the herd mean final score, registry status, and number of appraisals for the herd-classification date. Preadjustment of this type is independent of the evaluation model and therefore does not account for genetic or other (co)variances among observations. Simultaneous estimation of the HV adjustments allows updated estimates of genetic values to improve estimates of the variances. In addition, preadjustment requires a priori estimates of adjustment factors that may become outdated.

Meuwissen et al. (1996) developed a method for stabilizing of heterogeneous (co)variances simultaneously with the computation of the genetic evaluations. Gengler et al. (2000) applied this technique to Jersey type data. The objectives of this study were to describe its implementation for a Jersey type evaluation and assess its impact on predicting future progeny and the variance of Mendelian sampling. 
Table 1. Numbers of cows and bulls represented in the data by birth year group for animals born 1981 and later

\begin{tabular}{lrll}
\hline Birth years & \multicolumn{1}{c}{ Cows } & $\begin{array}{l}\text { Appraisals/ } \\
\text { cow }\end{array}$ & $\begin{array}{l}\text { Bulls with } \\
\geq 5 \text { daughters }\end{array}$ \\
\hline 1981 to 1985 & 75,603 & 1.88 & 1,213 \\
1986 to 1990 & 89,365 & 1.73 & 1,232 \\
1991 to 1995 & 99,043 & 1.75 & 1,414 \\
1996 to 2000 & 117,179 & 1.70 & 1,387 \\
2001 to $2005^{1}$ & 58,716 & 1.37 & 27 \\
Total & 439,906 & & 5,273 \\
\hline
\end{tabular}

${ }^{1}$ Includes appraisals through June 2005.

\section{MATERIALS AND METHODS}

\section{Data}

The 14 linear type traits analyzed by USDA for the Jersey breed include stature, strength, dairy form, foot angle, rear legs (side view), rump angle, rump width, fore udder attachment, rear udder height, rear udder width, udder depth, udder cleft, front teat placement, and teat length. Scoring for most traits was begun in the early 1980s; however, scoring for teat length did not begin until the late 1980 s. Therefore, many type records prior to 1990 are missing observations for that trait. Most linear type traits are scored from 1 to 50. However, stature may be scored as high as 80 . The range was extended to accommodate crossbred cows. As data from crossbred cows accumulate, consideration of breed composition in both the mean and variance models could improve accuracy. Future research will address the impacts of crossbreeding on type evaluations. Final score is computed from linear type scores. Data were provided by the American Jersey Cattle Association and were the same data as used for the August 2005 USDA genetic evaluations. Table 1 reports the numbers of cows and bulls represented in the data by birth period. Only first and second parities were used for Jersey type evaluations.

\section{Statistical Analyses}

Type Trait Model. The genetic evaluation method with HV adjustments consisted of adjustments for age and lactation stage followed by 3 interdependent iterative systems: solution of regular mixed model equations, updates of canonical traits to account for missing original traits, and updates of adjustment factors for HV. Age and lactation stage were not included in the $\mathrm{HV}$ adjustment to avoid scaling their effects.

Mixed Model Equations. The following multitrait (single trait for final score) animal model (Gengler et al., 1999) was applied for all traits:

$$
\mathbf{y}=\mathbf{X h}+\mathbf{S} \mathbf{s}+\mathbf{Z} \mathbf{p}+\mathbf{Z}^{*} \mathbf{u}+\mathbf{e}
$$

where $\mathbf{y}$ is the vector of type records; $\mathbf{h}$ is the vector of fixed effects of the interaction of herd, date scored, and parity (first or later) group; $\mathbf{s}$ is the vector of random effects of the interaction of herd and sire; $\mathbf{p}$ is the vector of random effects of the permanent environment; $\mathbf{u}$ is the vector of random additive genetic effects of animals and genetic groups ( $\mathbf{u}=\mathbf{a}+\mathbf{Q g}$, where $\mathbf{a}$ is the vector of random additive genetic effects of animals expressed as deviations from group means, $\mathbf{g}$ is the vector of fixed effects of genetic groups, and $\mathbf{Q}$ is the incidence matrix that links $\mathbf{g}$ with $\mathbf{u}) ; \mathbf{X}, \mathbf{S}, \mathbf{Z}$, and $\mathbf{Z}^{*}$ are incidence matrices that associate $\mathbf{h}, \mathbf{s}, \mathbf{p}$, and $\mathbf{u}$, respectively, with $\mathbf{y}$; and $\mathbf{e}$ is the vector of random residual effects.

For cows older than the highest age group within the parity, the parity was increased because birth dates were assumed to be more reliable than lactation numbers; even if a lactation number is correct, a very old first-lactation cow is best grouped with second-lactation cows. Additive corrections were applied for age and stage of lactation. These correction factors were obtained with a model that included age and stage effects in addition to those in Model 1; however, it was solved without correction for HV. These values were not updated each quarterly evaluation. Seventeen genetic groups were defined based on birth year $(\leq 1966,1967$

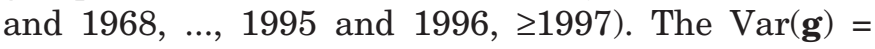
$\mathbf{A} \sigma_{\mathrm{g}}^{2}$. Inbreeding was accounted for in the construction of $\mathbf{A}^{-1}$.

The model for a particular trait $t$ may be referred to as:

$$
\mathbf{y}_{\mathrm{t}}=\mathbf{M m}_{\mathrm{t}}+\mathbf{e}_{\mathrm{t}}
$$

where $\mathbf{M}$ is a design matrix grouping $\mathbf{X}, \mathbf{H}, \mathbf{Z}$, and $\mathbf{Z}^{*}$; and $\mathbf{m}$ is a vector of all the solutions. A canonical transformation based on multiple diagonalization (Misztal et al., 1995) of $\operatorname{Var}(\mathbf{s}), \operatorname{Var}(\mathbf{p}), \operatorname{Var}(\mathbf{g})$, and $\operatorname{Var}(\mathbf{e})$ was applied to transform the $t$ observed traits for animal $i$ in environment $j$ (contemporary group) into $t$ unrelated traits $\left(\mathrm{y}_{\mathrm{Q}_{\mathrm{ij}}}\right)$ with a residual variance of $1 \mathrm{using}$ $\mathbf{y}_{Q_{i j}}=\mathbf{Q} \mathbf{y}_{i j}$, where $\mathbf{Q}$ is the transformation matrix and $\mathbf{y}_{\mathrm{ij}}$ is the vector of original traits. Where traits were missing, canonical observations were calculated from the observed original traits $\left.\left(\mathbf{y}_{\mathrm{ij}}^{0}\right)\right)$ and the current solutions on the transformed canonical scales using the equation of Ducrocq and Besbes (1993):

$$
\mathbf{y}_{Q_{i j}}=\mathbf{Q}_{1} \mathbf{y}_{\mathrm{ij}}^{0}+\mathbf{Q}_{2} \mathbf{M}_{j} \hat{\mathbf{m}}_{\mathrm{Q}_{\mathrm{ij}}}
$$

where $\hat{\mathrm{m}}_{\mathrm{Q}_{\mathrm{ij}}}$ are the solutions on the transformed scale. The $t$ mixed-model equation systems were then solved based on the general model: 


$$
\mathbf{y}_{Q_{i j}}=M_{Q_{i j}}+\mathbf{e}_{Q_{i j}}
$$

with continuous updating for missing traits.

Integrated HV Adjustment. Using the HV model proposed by Meuwissen et al. (1996), Model 2 can be written on a canonical scale as:

$$
\mathbf{y}_{\mathrm{Q}_{\mathrm{ij}}}=\Gamma_{\mathrm{j}}\left(\mathbf{M m}_{\mathrm{Q}_{\mathrm{ij}}}^{\mathrm{a}}+\mathbf{e}_{\mathrm{Q}_{\mathrm{ij}}}^{\mathrm{a}}\right)
$$

where superscript a denotes adjusted and $\Gamma_{\mathrm{j}}=$ $\operatorname{diag}\left[\exp \left(\gamma_{\mathrm{jt}} / 2\right)\right]$, which scales all effects for contemporary group $\mathrm{j}$ and canonical trait $\mathrm{t}$ by $\exp \left(\gamma_{\mathrm{jt}} / 2\right)$ and the associated variances by $\exp \left(\gamma_{\mathrm{jt}}\right)$. Because all associated variances were scaled identically, the transformation matrix $\mathbf{Q}$ remained appropriate.

The influence of the mean on the HV adjustment system was addressed by expressing each original trait as a deviation from its overall mean. Because data were corrected for age and lactation stage before analysis, it was possible to define heterogeneity subclasses according to contemporary groups. For traits not missing on the original scale, a transformed record adjusted for $\mathrm{HV}, \mathbf{y}_{\mathrm{Q}_{\mathrm{ij}}}^{\mathrm{a}}$, was calculated as:

$$
\mathbf{y}_{\mathrm{Q}_{\mathrm{ij}}}^{\mathrm{a}}=\Gamma_{\mathrm{j}}^{-1} \mathbf{Q}\left(\mathbf{y}_{\mathrm{ij}}^{0}-\overline{\mathbf{y}}^{0}\right) .
$$

Where traits were missing, an estimate of $\mathbf{y}_{\mathrm{Q}_{\mathrm{ij}}}^{\mathrm{a}}$ was calculated as:

$$
\mathbf{y}_{\mathrm{Q}_{\mathrm{ij}}}^{\mathrm{a}}=\Gamma_{\mathrm{j}}^{-1}\left[\mathbf{Q}_{1}\left(\mathbf{y}_{\mathrm{ij}}^{0}-\overline{\mathbf{y}}^{0}\right)+\mathbf{Q}_{2} \Gamma_{\mathrm{j}} \mathbf{M}_{\mathrm{j}} \hat{\mathbf{m}}_{\mathrm{Q}_{\mathrm{ij}}}^{\mathrm{a}}\right]
$$

Update of Heterogeneity Factors. Based on Meuwissen et al. (1996), a heterogeneity parameter z could be developed:

$$
\mathbf{z}_{\mathrm{jt}}=\left[\left(\mathbf{y}_{\mathrm{Q}_{\mathrm{jt}}}^{\mathrm{a}}\right)^{\prime} \mathbf{D}_{\mathrm{jt}} \mathbf{e}_{\mathrm{Q}_{\mathrm{jt}}}^{\mathrm{a}}-\sum_{\mathrm{k}=1}^{\mathrm{n}_{\mathrm{j}}} \lambda_{\mathrm{jtk}}\right] / 2,
$$

where $\mathbf{D}_{\mathbf{j t}}=\operatorname{diag}\left(\lambda_{\mathrm{jtk}}\right)$, a diagonal matrix with element $\lambda_{\text {jtk }}$ (weight associated with observation $\mathrm{k}$ in contemporary group $j$ for trait $t$ ). The weight was assumed to be 1 if no original traits were missing and to be $<1$ if an original trait was missing. Computation of $\lambda_{\text {jtk }}$ followed the methodology proposed in Gengler and Misztal (1996). The variance associated with the heterogeneity parameter was estimated as:

$$
\operatorname{Var}\left(\mathbf{z}_{\mathrm{jt}}\right)=\left[\left(\hat{\mathbf{m}}_{\mathrm{Q}_{\mathrm{jt}}}\right)^{\prime} \mathbf{D}_{\mathrm{jt}} \hat{\mathbf{m}}_{\mathrm{Q}_{\mathrm{jt}}}+2 \sum_{\mathrm{k}=1}^{\mathrm{n}_{\mathrm{j}}} \lambda_{\mathrm{jtk}}\right] / 4 .
$$

A feature of the method of Meuwissen et al. (1996) is that the modeling of the heterogeneity parameter uses a weighted mixed model on constructed variates obtained by summing the current $\gamma_{\mathrm{jt}}$ with the remaining heterogeneity within contemporary group:

$$
\left(\mathbf{S}^{\prime} \mathbf{W}_{\mathrm{t}} \mathbf{S}+\boldsymbol{\Lambda}_{\mathrm{t}}^{-1}\right) \boldsymbol{\beta}_{\mathrm{t}}=\mathbf{S}^{\prime} \mathbf{W}_{\mathrm{t}}\left[\boldsymbol{\Gamma}_{\mathrm{t}}+\mathbf{W}_{\mathrm{t}}^{-1} \mathbf{z}_{\mathrm{t}}\right]
$$

where $\boldsymbol{\beta}_{\mathrm{t}}$ is a vector of solutions; $\mathbf{S}$ is the design matrix linking constructed variates and $\boldsymbol{\beta}_{\mathrm{t}} ; \mathbf{W}_{\mathrm{t}}=\operatorname{diag}\left[\operatorname{Var}\left(\mathbf{z}_{\mathrm{jt}}\right]\right.$ diagonal matrix iterative weights; and $\boldsymbol{\Lambda}_{\mathrm{t}}=\operatorname{Var}\left(\boldsymbol{\beta}_{\mathrm{t}}\right)$.

In contrast to Meuwissen et al. (1996), $\gamma_{\mathrm{jt}}$ were scaled toward a common base, $\gamma_{j t}=\mathbf{S} \boldsymbol{\beta}_{\mathrm{t}}-\gamma_{\mathrm{t}}^{\text {base }}$, because mean variances had to be retained for back solving. In addition, scaling toward a common base was conceptually similar to the approaches in other studies of type data (e.g., Koots et al., 1994; Weigel and Lawlor, 1994). Because the approach was similar to an additive base change before and after solving the mixed model equations, the definition of the base had no influence on the heterogeneity factor solutions.

Heterogeneity Model. Most studies of type traits have applied a structural model (e.g., Koots et al., 1994; Weigel and Lawlor, 1994). The heterogeneity model presented here contains fixed effects to pool information across contemporary groups and a random effect that regresses the observed heterogeneity for a given herdappraisal date toward the fixed effects. The fixed effects are the size of the contemporary group by parity; the mean final score of the contemporary group by parity; the month of appraisal by parity; and the 6-mo season, year, and parity class. The ranges of contemporary group size and mean final score were separated into 10 groups of equal size within parity. Because the random effect was defined as herd-appraisal date (did not include parity), first- and second-parity classes were assumed to have the same variance except for systematic variance differences among parities that were modeled by the fixed effects. This is reasonable because firstand second-lactation scorings are mandatory in Jerseys. This heterogeneity model is a combination of the one used by Koots et al. (1994) for the random effect and the one by Weigel and Lawlor (1994) for fixed effects. The variance model provides a predicted value that pools a priori knowledge from fixed effects and directly observed heterogeneity. Therefore, it is conceptually close to the Bayesian approach used for the final score of US Holsteins (Weigel and Lawlor, 1994).

Ideally, the variance components necessary for the variance model should be estimated jointly (Meuwissen et al., 1996). To achieve this, the required repeatabilities of heterogeneity of variance were estimated using Method R (Reverter et al., 1994), because this method could be easily integrated into the algorithm. 
Computational Aspects. The publicly available computer program MTJAAM (Gengler et al., 1999) was modified for this analysis. Estimation of adjustment factors was placed in a subroutine. To enhance convergence speed and stability, the relaxation factor used for the second-order Jacobi procedure was adjusted according to the value of the convergence criterion of the genetic effect. The relaxation factor was computed as $1+0.11\left[-\log _{10}\right.$ (convergence) $]$ at every iteration, with a maximum of 1.9 where the convergence criterion was the squared relative differences between solutions of the genetic effect. Heterogeneity convergence was monitored, and heterogeneity adjustment updates were stopped if this convergence was below a threshold or did not improve for 5 rounds. A minimum of 5 heterogeneity rounds was imposed to avoid convergence problems.

\section{Genetic Trend}

Mean EBV were calculated by birth year. Genetic trend was calculated by regressing these means on birth year and birth year squared. The slope was evaluated at year 2000, the most recent year with complete data. Data were restricted to birth years 1981 through 2001 to eliminate years with few observations. Slope also was calculated using only birth years 1996 through 2000 to better determine the slope in the most recent data.

\section{Comparison of Evaluations With and Without HV Adjustment}

To evaluate the benefit of the HV adjustment, evaluations also were calculated with and without HV adjustment from a truncated data set in which appraisals from August 2001 and later were removed. The truncation on appraisal date was imposed to enable calculation of parent averages of recent animals that did not include any data from their own appraisals or those of their progeny but still had evaluations that included their own information in the complete data. Correlations between parent averages from the truncated sets and EBV from the complete sets were calculated from both evaluations with and without $\mathrm{HV}$ adjustment. To remove the effect of genetic trend on correlations, birthyear means were subtracted from the EBV and parent averages before calculating the correlations. Mean differences between $\mathrm{HV}$-adjusted and HV-unadjusted EBV and standard deviations of those differences also were calculated and stratified by reliability, year of birth, and mean daughter final score.

The International Bull Evaluation Service (Interbull, Uppsala, Sweden) requires new or changed evaluation systems to be validated by trend tests. Interbull Method
3 (Boichard et al., 1995; Fikse et al., 2003) involves calculating a test statistic based on a comparison of evaluations separated by $4 \mathrm{yr}$, and it considers the amount of new information added by year. This statistic was calculated for evaluations with and without the HV adjustment. Interbull Method 1 (Boichard et al., 1995) compares trends from evaluations using first records only with ones using all data. This test was applied to the HV-adjusted evaluations to determine whether they met Interbull requirements, not to determine the effect of $\mathrm{HV}$ adjustment.

\section{Mendelian Sampling}

Use of Mendelian-sampling (evaluation minus mean of parent evaluations) standard deviations as a test for the quality of model fit has been proposed recently (e.g., Miglior et al., 2002; Fikse et al., 2003). Mendelian-sampling standard deviations were studied for cows born in 1981 and later. Means, standard deviations, and the linear regression of the Mendelian-sampling standard deviations on birth year were calculated. Mendeliansampling standard deviations should be stable over time, and the Mendelian-sampling mean should be zero and show no trend.

\section{RESULTS}

\section{Comparison of Evaluations With and Without HV Adjustment}

The evaluation with $\mathrm{HV}$ adjustment computation took approximately $17 \%$ longer per iteration ( $1.7 \mathrm{~s}$ total time per iteration on an IBM model 366 computer) than the evaluation without adjustment; however, more than double the number of iterations (168) were done. Problems with convergence can occur, and the starting values for the iteration can affect the outcome. Therefore, a run without HV adjustment was found to be useful to create adequate starting values to begin adjustment for HV from stable solutions. Also, experience showed that updating repeatabilities of the heterogeneity of variance using Method $R$ on every run was not necessary; therefore, we used the same repeatabilities, which was analogous to using the same variance components.

The adjustment slightly improved correlations within birth year for 5,273 AI bulls born from 1981 to 2000 with $\geq 5$ appraised daughters over all traits, but did not improve the correlations for final score, strength, dairy form, teat length, or foot angle. For bulls born from 1981 to 2001, correlations within birth year between HV-adjusted parent average and EBV (Table 2) ranged from 0.735 for thurl width to 0.908 for rear legs (side view). In contrast, correlations for HV-unadjusted parent average and EBV ranged from 0.732 for 
Table 2. Correlations within birth year for bulls between parent average from truncated data and EBV from full data with and without heterogeneous variance (HV) adjustment

\begin{tabular}{llll}
\hline & \multicolumn{2}{c}{ HV adjustment } & \\
\cline { 2 - 3 } Trait name & Yes & No & Difference \\
\hline Final score & 0.786 & 0.793 & -0.007 \\
Stature & 0.771 & 0.770 & 0.001 \\
Strength & 0.748 & 0.749 & -0.001 \\
Dairy form & 0.826 & 0.829 & -0.003 \\
Foot angle & 0.837 & 0.843 & -0.006 \\
Rear legs (side view) & 0.908 & 0.907 & 0.001 \\
Rump angle & 0.828 & 0.818 & 0.010 \\
Rump width & 0.735 & 0.732 & 0.003 \\
Fore udder attachment & 0.833 & 0.830 & 0.003 \\
Rear udder height & 0.766 & 0.759 & 0.007 \\
Rear udder width & 0.796 & 0.794 & 0.002 \\
Udder depth & 0.832 & 0.827 & 0.005 \\
Udder clef & 0.798 & 0.791 & 0.007 \\
Front teat placement & 0.820 & 0.817 & 0.003 \\
Teat length & 0.800 & 0.811 & -0.011 \\
\hline \multicolumn{1}{l}{ lHV corth }
\end{tabular}

${ }^{1} \mathrm{HV}$ correlation - without-HV correlation.

thurl width to 0.907 for rear legs (side view). Correlations (results not shown) across birth year were higher for both $\mathrm{HV}$-adjusted and $\mathrm{HV}$-unadjusted evaluations because of genetic trend ( $\mathrm{HV}$-adjusted correlations ranged from 0.852 for strength to 0.966 for dairy form). The HV improvement also was greater, improving the correlation of parent average to future evaluation by a mean of 0.0039 over all traits; still, teat length and foot angle were not improved.

\section{Genetic Trend}

Estimates of genetic trend for cows with and without HV adjustment are given in Table 3 for 15 traits over birth years from 1981 to 2000 and 1996 to 2000 . The trend lines were largely linear, but quadratic coefficients did increase the adjusted $R^{2}$ for most traits with the application of $\mathrm{HV}$ adjustments. The adjusted $\mathrm{R}^{2}$ was greater than 0.97 for 10 traits over all years and was not below 0.85 for any trait. The 5 -yr trend was less stable than the 20-yr trend for both HV-adjusted and HV-unadjusted evaluations, but $\mathrm{HV}$-adjusted trends were generally lower than those for the HVunadjusted evaluations.

Annual trends for bull EBV (Table 4) were generally lower than those for cows and the trend over $20 \mathrm{yr}$ from the evaluation with HV adjustment was lower than the trend from $\mathrm{HV}$-unadjusted evaluations for all traits except rump width, for which the trend was greater by $0.0004 / y r$. The greatest reduction in trend was for dairy form $(0.0023$ lower, or $22 \%)$. The trend over 5 yr showed a slightly higher trend with HV adjustment for a few traits.

As shown in Table 5, mean differences between HVadjusted and HV-unadjusted EBV and standard deviations of those differences for most traits were highest for bulls with reliabilities below $81 \%$. Evaluations for bulls with higher reliabilities were not regressed as strongly toward the parent average; therefore, the differences caused by the HV adjustment were expressed more in progeny information. Bulls with the highest reliabilities did not have great changes in EBV because with a large number of progeny, the effects of HV adjustments would tend to be averaged out. The HV-adjusted EBV for final score ranged from -8.74 to 5.77 after base adjustment, whereas HV-unadjusted EBV for final score ranged from -10.59 to 5.63 with a base adjustment.

Table 3. Trend in EBV for cows with and without heterogeneous variance (HV) adjustment from a quadratic regression on birth year evaluated at year 2000

\begin{tabular}{|c|c|c|c|c|c|c|}
\hline \multirow[b]{3}{*}{ Trait } & \multicolumn{3}{|c|}{1981 to 2000} & \multicolumn{3}{|c|}{1996 to 2000} \\
\hline & \multicolumn{2}{|c|}{ HV adjustment } & \multirow[b]{2}{*}{ Difference $^{1}$} & \multicolumn{2}{|c|}{ HV adjustment } & \multirow[b]{2}{*}{ Difference } \\
\hline & Yes & No & & Yes & No & \\
\hline Final score & 0.0015 & 0.0013 & 0.0003 & 0.0017 & -0.0028 & 0.0045 \\
\hline Stature & 0.0093 & 0.0104 & -0.0011 & 0.0061 & 0.0083 & -0.0022 \\
\hline Strength & 0.0050 & 0.0055 & -0.0005 & 0.0058 & 0.0074 & -0.0016 \\
\hline Dairy form & -0.0027 & -0.0030 & 0.0003 & -0.0039 & -0.0060 & 0.0021 \\
\hline Foot angle & 0.0042 & 0.0051 & -0.0010 & 0.0012 & 0.0013 & 0.0000 \\
\hline Rear legs (side view) & -0.0011 & -0.0016 & 0.0005 & -0.0117 & -0.0135 & 0.0018 \\
\hline Rump angle & -0.0008 & -0.0007 & -0.0001 & -0.0129 & -0.0137 & 0.0008 \\
\hline Rump width & 0.0024 & 0.0026 & -0.0001 & -0.0068 & -0.0081 & 0.0013 \\
\hline Fore udder attachment & 0.0056 & 0.0070 & -0.0014 & -0.0082 & -0.0106 & 0.0024 \\
\hline Rear udder height & 0.0023 & 0.0032 & -0.0009 & -0.0033 & -0.0060 & 0.0027 \\
\hline Rear udder width & 0.0014 & 0.0019 & -0.0005 & 0.0006 & -0.0005 & 0.0010 \\
\hline Udder depth & 0.0068 & 0.0080 & -0.0012 & -0.0058 & -0.0077 & 0.0018 \\
\hline Udder cleft & 0.0007 & 0.0011 & -0.0004 & 0.0014 & 0.0014 & -0.0001 \\
\hline Front teat placement & 0.0046 & 0.0058 & -0.0012 & -0.0059 & -0.0078 & 0.0020 \\
\hline Teat length & 0.0034 & 0.0042 & -0.0007 & -0.0026 & -0.0037 & 0.0010 \\
\hline
\end{tabular}

${ }^{1} \mathrm{HV}$ EBV trend - without-HV EBV trend. 
Table 4. Trend in EBV for AI bulls with $\geq 5$ appraised daughters with and without heterogeneous variance (HV) adjustment from a quadratic regression on birth year evaluated at year 2000

\begin{tabular}{|c|c|c|c|c|c|c|}
\hline \multirow[b]{3}{*}{ Trait } & \multicolumn{3}{|c|}{1981 to 2000} & \multicolumn{3}{|c|}{1996 to 2000} \\
\hline & \multicolumn{2}{|c|}{ HV adjustment } & \multirow[b]{2}{*}{ Difference $^{1}$} & \multicolumn{2}{|c|}{ HV adjustment } & \multirow[b]{2}{*}{ Difference } \\
\hline & Yes & No & & Yes & No & \\
\hline Final score & -0.0016 & -0.0029 & 0.0013 & 0.0182 & 0.0156 & 0.0026 \\
\hline Stature & 0.0083 & 0.0091 & -0.0008 & -0.0253 & -0.0262 & 0.0009 \\
\hline Strength & 0.0045 & 0.0048 & -0.0003 & -0.0096 & -0.0113 & 0.0017 \\
\hline Dairy form & -0.0080 & -0.0103 & 0.0023 & 0.0424 & 0.0436 & -0.0012 \\
\hline Foot angle & 0.0036 & 0.0043 & -0.0007 & 0.0017 & 0.0039 & -0.0022 \\
\hline Rear legs (side view) & -0.0028 & -0.0036 & 0.0008 & 0.0090 & 0.0091 & -0.0001 \\
\hline Rump angle & -0.0015 & -0.0017 & 0.0002 & -0.0120 & -0.0127 & 0.0007 \\
\hline Rump width & 0.0007 & 0.0004 & 0.0004 & -0.0179 & -0.0224 & 0.0045 \\
\hline Fore udder attachment & 0.0058 & 0.0069 & -0.0011 & -0.0513 & -0.0573 & 0.0060 \\
\hline Rear udder height & -0.0009 & -0.0015 & 0.0006 & 0.0079 & 0.0069 & 0.0009 \\
\hline Rear udder width & -0.0026 & -0.0037 & 0.0011 & 0.0336 & 0.0350 & -0.0014 \\
\hline Udder depth & 0.0081 & 0.0093 & -0.0012 & -0.0565 & -0.0590 & 0.0025 \\
\hline Udder cleft & 0.0022 & 0.0024 & -0.0002 & 0.0087 & 0.0079 & 0.0008 \\
\hline Front teat placement & 0.0056 & 0.0064 & -0.0008 & -0.0150 & -0.0208 & 0.0057 \\
\hline Teat length & 0.0035 & 0.0043 & -0.0008 & -0.0163 & -0.0195 & 0.0032 \\
\hline
\end{tabular}

${ }^{1} \mathrm{HV}$ EBV trend - without-HV EBV trend.

When stratified by birth year, the mean differences in EBV were generally highest for bulls born from 1981 to 1985 (Table 6). The evaluations of older bulls tended to increase and those of younger bulls decreased with HV adjustment, consistent with the reduction in estimated genetic trend. The standard deviations of differences were largest for most traits for bulls born from 1986 through 1990 . As with the stratification by reliability, bulls born in the most recent years did not have large numbers of progeny, so they deviated less from their respective parent averages. Bulls born in the earliest years would have progeny well distributed over the various $\mathrm{HV}$ levels, leaving the 2 middle groups as the ones with greatest potential for change. When stratified by base-adjusted final score EBV, mean differences between adjusted and unadjusted final scores decreased in magnitude as they approached the mean EBV, then increased as mean final scores increased (data not shown).

The HV-adjusted mean differences for EBV averaged higher for most traits for bulls with daughters with the lowest mean final scores (Table 7). Standard deviations of the differences were also largest for those bulls. Weigel and Lawlor (1994) showed that for type data,

Table 5. Differences between bull EBV calculated with and without heterogeneous variance (HV) adjustment, and their SD by reliability of final score

\begin{tabular}{|c|c|c|c|c|c|c|c|c|}
\hline \multirow[b]{3}{*}{ Trait } & \multicolumn{8}{|c|}{ Reliability of final score } \\
\hline & \multicolumn{2}{|l|}{$\leq 70 \%$} & \multicolumn{2}{|c|}{71 to $80 \%$} & \multicolumn{2}{|c|}{81 to $90 \%$} & \multicolumn{2}{|c|}{$>90 \%$} \\
\hline & Difference $^{1}$ & SD & Difference & SD & Difference & SD & Difference & SD \\
\hline Final score & 0.026 & 0.034 & 0.023 & 0.039 & 0.019 & 0.036 & 0.012 & 0.029 \\
\hline Stature & 0.007 & 0.043 & 0.011 & 0.048 & 0.010 & 0.043 & 0.006 & 0.039 \\
\hline Strength & 0.004 & 0.030 & 0.007 & 0.035 & 0.005 & 0.031 & 0.005 & 0.029 \\
\hline Dairy form & 0.045 & 0.061 & 0.035 & 0.061 & 0.027 & 0.056 & 0.009 & 0.041 \\
\hline Foot angle & 0.005 & 0.027 & 0.009 & 0.031 & 0.007 & 0.031 & 0.003 & 0.029 \\
\hline Rear legs (side view) & 0.003 & 0.023 & -0.002 & 0.026 & -0.002 & 0.029 & -0.002 & 0.028 \\
\hline Rump angle & 0.005 & 0.035 & 0.003 & 0.042 & 0.002 & 0.044 & 0.006 & 0.041 \\
\hline Rump width & 0.008 & 0.026 & 0.011 & 0.030 & 0.009 & 0.028 & 0.007 & 0.027 \\
\hline Fore udder attachment & 0.002 & 0.035 & 0.009 & 0.040 & 0.011 & 0.043 & 0.006 & 0.041 \\
\hline Rear udder height & 0.037 & 0.051 & 0.033 & 0.054 & 0.030 & 0.052 & 0.016 & 0.045 \\
\hline Rear udder width & 0.040 & 0.050 & 0.033 & 0.052 & 0.030 & 0.048 & 0.015 & 0.040 \\
\hline Udder depth & -0.005 & 0.044 & 0.001 & 0.051 & 0.004 & 0.057 & 0.002 & 0.047 \\
\hline Udder cleft & 0.015 & 0.028 & 0.013 & 0.033 & 0.014 & 0.032 & 0.006 & 0.030 \\
\hline Front teat placement & 0.013 & 0.037 & 0.015 & 0.043 & 0.016 & 0.043 & 0.007 & 0.041 \\
\hline Teat length & 0.002 & 0.034 & 0.002 & 0.040 & 0.002 & 0.043 & 0.002 & 0.038 \\
\hline Number of bulls & \multicolumn{2}{|l|}{3,325} & \multicolumn{2}{|c|}{1,112} & \multicolumn{2}{|l|}{542} & \multicolumn{2}{|c|}{285} \\
\hline
\end{tabular}

${ }^{1} \mathrm{HV}$ EBV - without-HV EBV. 
Table 6. Means and SD of differences between bull EBV calculated with and without heterogeneous variance (HV) adjustment by birth-year group

\begin{tabular}{|c|c|c|c|c|c|c|c|c|}
\hline \multirow[b]{3}{*}{ Trait } & \multicolumn{8}{|c|}{ Birth years } \\
\hline & \multicolumn{2}{|c|}{1981 to 1985} & \multicolumn{2}{|c|}{1986 to 1990} & \multicolumn{2}{|c|}{1991 to 1995} & \multicolumn{2}{|c|}{1996 to 2000} \\
\hline & Difference $^{1}$ & SD & Difference & SD & Difference & $\mathrm{SD}$ & Difference & SD \\
\hline Final score & 0.054 & 0.033 & 0.031 & 0.035 & 0.011 & 0.029 & 0.003 & 0.018 \\
\hline Stature & 0.015 & 0.047 & 0.019 & 0.050 & 0.004 & 0.033 & -0.005 & 0.042 \\
\hline Strength & 0.009 & 0.036 & 0.009 & 0.037 & 0.003 & 0.024 & -0.001 & 0.026 \\
\hline Dairy form & 0.108 & 0.044 & 0.056 & 0.055 & 0.008 & 0.037 & -0.003 & 0.029 \\
\hline Foot angle & 0.015 & 0.029 & 0.009 & 0.034 & 0.007 & 0.026 & -0.005 & 0.019 \\
\hline Rear legs (side view) & 0.009 & 0.030 & 0.001 & 0.029 & -0.003 & 0.022 & -0.001 & 0.015 \\
\hline Rump angle & 0.014 & 0.040 & 0.009 & 0.051 & -0.001 & 0.034 & -0.002 & 0.022 \\
\hline Rump width & 0.019 & 0.030 & 0.012 & 0.032 & 0.005 & 0.021 & 0.002 & 0.023 \\
\hline Fore udder attachment & 0.010 & 0.040 & 0.012 & 0.043 & 0.007 & 0.034 & -0.008 & 0.030 \\
\hline Rear udder height & 0.083 & 0.039 & 0.051 & 0.048 & 0.014 & 0.037 & -0.003 & 0.033 \\
\hline Rear udder width & 0.088 & 0.036 & 0.053 & 0.047 & 0.014 & 0.034 & -0.001 & 0.027 \\
\hline Udder depth & -0.005 & 0.049 & -0.001 & 0.060 & 0.005 & 0.042 & -0.008 & 0.035 \\
\hline Udder cleft & 0.029 & 0.031 & 0.021 & 0.030 & 0.009 & 0.025 & 0.000 & 0.023 \\
\hline Front teat placement & 0.027 & 0.041 & 0.026 & 0.043 & 0.011 & 0.034 & -0.006 & 0.028 \\
\hline Teat length & -0.001 & 0.049 & 0.007 & 0.040 & 0.001 & 0.027 & 0.003 & 0.026 \\
\hline Number of bulls & \multicolumn{2}{|c|}{1,210} & \multicolumn{2}{|c|}{1,232} & \multicolumn{2}{|c|}{1,412} & \multicolumn{2}{|c|}{1383} \\
\hline
\end{tabular}

${ }^{1} \mathrm{HV}$ EBV - without-HV EBV.

Table 7. Differences between bull EBV calculated with and without heterogeneous variance (HV) adjustment and their SD by mean daughter final score

\begin{tabular}{|c|c|c|c|c|c|c|c|c|c|}
\hline Trait & & \multicolumn{8}{|c|}{ Mean daughter final score } \\
\hline Final score & Difference $^{1}$ & 0.063 & 0.035 & 0.025 & 0.012 & 0.005 & 0.003 & 0.005 & 0.009 \\
\hline \multirow{2}{*}{ Stature } & Difference & 0.030 & 0.019 & 0.007 & 0.007 & 0.000 & -0.002 & -0.008 & -0.015 \\
\hline & SD & 0.051 & 0.049 & 0.042 & 0.039 & 0.038 & 0.031 & 0.038 & 0.039 \\
\hline Strength & Difference & 0.018 & 0.010 & 0.004 & 0.003 & 0.000 & -0.001 & -0.002 & -0.005 \\
\hline Dairy form & SD & 0.055 & 0.052 & 0.053 & 0.052 & 0.044 & 0.041 & 0.040 & 0.036 \\
\hline \multirow[t]{2}{*}{ Foot angle } & Difference & 0.019 & 0.014 & 0.010 & 0.007 & 0.000 & -0.003 & -0.005 & -0.009 \\
\hline & SD & 0.033 & 0.032 & 0.029 & 0.027 & 0.022 & 0.020 & 0.020 & 0.018 \\
\hline \multirow[t]{2}{*}{ Rear legs (side view) } & Difference & 0.003 & 0.001 & 0.001 & -0.001 & 0.000 & 0.001 & 0.002 & 0.004 \\
\hline & SD & 0.031 & 0.030 & 0.027 & 0.025 & 0.020 & 0.018 & 0.018 & 0.016 \\
\hline \multirow[t]{2}{*}{ Rump angle } & Difference & 0.010 & 0.012 & 0.006 & 0.003 & 0.003 & 0.001 & -0.001 & -0.001 \\
\hline & SD & 0.049 & 0.046 & 0.041 & 0.038 & 0.032 & 0.027 & 0.024 & 0.024 \\
\hline Rear udder height & SD & 0.045 & 0.039 & 0.039 & 0.040 & 0.038 & 0.036 & 0.035 & 0.033 \\
\hline \multirow[t]{2}{*}{ Rear udder width } & Difference & 0.090 & 0.058 & 0.044 & 0.026 & 0.011 & 0.005 & 0.000 & 0.000 \\
\hline & $\mathrm{SD}$ & 0.042 & 0.039 & 0.040 & 0.040 & 0.036 & 0.033 & 0.033 & 0.031 \\
\hline \multirow{2}{*}{ Udder depth } & Difference & 0.004 & 0.003 & 0.003 & 0.002 & -0.002 & -0.008 & -0.013 & -0.020 \\
\hline & SD & 0.064 & 0.053 & 0.051 & 0.045 & 0.035 & 0.032 & 0.029 & 0.030 \\
\hline \multirow{2}{*}{ Udder cleft } & Difference & 0.036 & 0.023 & 0.019 & 0.011 & 0.004 & 0.001 & 0.000 & 0.000 \\
\hline & SD & 0.032 & 0.027 & 0.026 & 0.026 & 0.022 & 0.023 & 0.022 & 0.020 \\
\hline \multirow[t]{2}{*}{ Front teat placement } & Difference & 0.044 & 0.026 & 0.019 & 0.010 & 0.001 & -0.004 & -0.007 & -0.013 \\
\hline & SD & 0.044 & 0.038 & 0.036 & 0.031 & 0.028 & 0.027 & 0.027 & 0.025 \\
\hline \multirow{2}{*}{ Teat length } & Difference & 0.007 & 0.003 & 0.002 & 0.000 & 0.000 & 0.000 & 0.001 & 0.002 \\
\hline & SD & 0.046 & 0.043 & 0.040 & 0.034 & 0.031 & 0.026 & 0.026 & 0.023 \\
\hline Number of bulls & & 1,091 & 503 & 593 & 626 & 649 & 700 & 410 & 433 \\
\hline
\end{tabular}

${ }^{1} \mathrm{HV}$ EBV - without-HV EBV. 
Table 8. Trend in standard deviations of Mendelian sampling for cow EBV calculated with and without heterogeneous variance (HV) adjustment and EBV slope ratio by birth-year group

\begin{tabular}{|c|c|c|c|c|c|c|}
\hline \multirow[b]{3}{*}{ Trait } & \multicolumn{3}{|c|}{1981 to 2000} & \multicolumn{3}{|c|}{1996 to 2000} \\
\hline & \multicolumn{2}{|c|}{ HV adjustment } & \multirow{2}{*}{$\begin{array}{l}\text { HV slope/ } \\
\text { (no HV slope) } \\
\times 100 \%\end{array}$} & \multicolumn{2}{|c|}{ HV adjustment } & \multirow{2}{*}{$\begin{array}{l}\text { HV slope/ } \\
\text { (no HV slope) } \\
\times 100 \%\end{array}$} \\
\hline & Yes & No & & Yes & No & \\
\hline Final score & 0.0000 & -0.0018 & 16.8 & 0.0016 & 0.0139 & 14.8 \\
\hline Stature & 0.0001 & -0.0020 & 27.1 & -0.0042 & 0.0194 & -20.6 \\
\hline Strength & 0.0000 & -0.0016 & 32.7 & 0.0034 & 0.0175 & 30.9 \\
\hline Dairy form & -0.0002 & -0.0030 & 29.5 & -0.0066 & 0.0027 & -29.0 \\
\hline Foot angle & -0.0003 & -0.0013 & 28.1 & 0.0059 & 0.0158 & 46.6 \\
\hline Rear legs (side view) & -0.0001 & -0.0009 & 35.5 & -0.0001 & 0.0048 & 11.3 \\
\hline Rump angle & -0.0005 & -0.0033 & 31.7 & 0.0039 & 0.0229 & 22.2 \\
\hline Rump width & -0.0001 & -0.0015 & 34.4 & 0.0046 & 0.0164 & 39.1 \\
\hline Fore udder attachment & -0.0004 & -0.0028 & 23.3 & 0.0002 & 0.0154 & 12.6 \\
\hline Rear udder height & 0.0000 & -0.0029 & 10.4 & -0.0119 & 0.0050 & -51.1 \\
\hline Rear udder width & -0.0004 & -0.0031 & 23.4 & -0.0033 & 0.0085 & 24.1 \\
\hline Udder depth & -0.0008 & -0.0043 & 10.0 & -0.0027 & 0.0142 & -44.3 \\
\hline Udder cleft & 0.0002 & -0.0014 & 23.6 & 0.0068 & 0.0172 & 52.4 \\
\hline Front teat placement & 0.0000 & -0.0024 & 29.5 & 0.0037 & 0.0160 & 45.7 \\
\hline Teat length & -0.0016 & -0.0031 & 42.7 & 0.0133 & 0.0265 & 51.5 \\
\hline
\end{tabular}

herds with the highest final scores had the lowest variance. In this stratification on the mean final score, the bulls with daughters in the most extreme groups showed greater change than those with daughters in less extreme groups, as expected.

Mendelian sampling was calculated for cows born from 1981 through 2000 (Table 8). With HV adjustment, Mendelian-sampling standard deviations declined less over time than for unadjusted evaluations for all traits except rump width. The slope at year 2000 of Mendelian-sampling standard deviations from $\mathrm{HV}$-adjusted evaluations ranged from $10.0 \%$ for udder depth to $42.7 \%$ for teat length of the slope for unadjusted evaluations. Ideally, the Mendelian-sampling variance should be stable over time. The reduced slope of the Mendeliansampling standard deviations from the $\mathrm{HV}$-adjusted analysis for most traits is an indication that the adjustment more correctly models the data.

The Interbull trend validation was performed for stature and udder support. Evaluations with the HV adjustment passed both the Method 1 and Method 3 tests, indicating that the large changes in trend did not cause inconsistency in the trend either between first and all appraisals or over time within sire. The HV adjustment performed better for the Interbull Method 3 test for the 2 required traits. Both tests were performed to ensure Interbull compliance following adjustment.

\section{CONCLUSIONS}

Evaluations with HV adjustment were highly correlated with the evaluations without the adjustment, but differed in expected ways. The bulls with the greatest changes were generally those with the lowest mean daughter final scores. Records on daughters of these bulls received the most adjustment. Some reduction over time in Mendelian-sampling standard deviations is expected if older animals have higher reliability and lower inbreeding; however, those factors are unlikely to explain the higher slopes for EBV trend found in the evaluations without $\mathrm{HV}$ adjustment. Therefore, the lower slopes from the HV adjustment also indicate the superiority of the HV-adjusted evaluations. The reduction in estimates of genetic trend also indicates that the $\mathrm{HV}$ adjustment affected comparisons across time. These reductions in trend are likely due to changes in the variance of Mendelian sampling. The additional computations required are manageable. The starting values for the iteration may determine whether convergence is achieved. A run without HV adjustment may be useful to create adequate starting values. The HVadjusted evaluations were adopted as official for the Jersey breed for the May 2001 evaluation and for the other breeds for which USDA calculates evaluations for the February 2002 evaluation. This enhancement improved the accuracy of selection decisions based on type traits, particularly over time.

\section{ACKNOWLEDGMENTS}

N. Gengler, Chercheur Qualifié of the National Fund for Scientific Research (Brussels, Belgium), and T. Druet, Chargé de Recherches of the National Fund for Scientific Research (Brussels, Belgium), currently at the Institut National de la Recherche Agronomique (Jouy-en-Josas, France), acknowledge the financial support of their organizations. Partial funding provided 
by the American Jersey Cattle Association (Reynoldsburg, $\mathrm{OH}$ ) and manuscript review by Kent Weigel (University of Wisconsin, Madison) are also acknowledged.

\section{REFERENCES}

Bell, B. R., W. E. Vinson, J. M. White, H. D. Norman, and R. H. Kliewer. 1982. Effects of genetic merit of herdmates on sire summaries for type in Holstein cattle. J. Dairy Sci. 65:126-135.

Boichard, D., B. Bonaiti, A. Barbat, and S. Mattalia. 1995. Three methods to validate the estimation of genetic trend for dairy cattle. J. Dairy Sci. 78:431-437.

Ducrocq, V., and B. Besbes. 1993. Solution of multiple trait models with missing data on some traits. J. Anim. Breed. Genet. 110:81-92.

Fikse, W. F., L. Klei, Z. Liu, and P. G. Sullivan. 2003. Procedure for validation of trends in genetic variance. Interbull Bull. 31:30-36.

Gengler, N., T. Dusseldorf, G. R. Wiggans, J. R. Wright, and T. Druet. 2000. Multitrait genetic evaluation of Jersey type with integrated accounting for heterogeneous (co)variances. Interbull Bull. 25:108-122.

Gengler, N., T. Dusseldorf, G. R. Wiggans, J. R. Wright, and T. Druet. 2001. Heterogeneity of (co)variance components for Jersey type traits. J. Dairy Sci. 84:1772. Online. Available: http://jds.fass.org/

Gengler, N., and I. Misztal. 1996. Approximation of reliability for multiple-trait animal models with missing data by canonical transformation. J. Dairy Sci. 79:317-328.
Gengler, N., G. R. Wiggans, and J. R. Wright. 1999. Animal model genetic evaluation of type traits for five dairy cattle breeds. J. Dairy Sci. 82:1350. Online. Available: http://jds.fass.org/

Gengler, N., G. R. Wiggans, J. R. Wright, H. D. Norman, and C. W. Wolfe. 1997a. Application of canonical transformation with missing values to multitrait evaluation of Jersey type. J. Dairy Sci. 80:2563-2571.

Gengler, N., G. R. Wiggans, J. R. Wright, H. D. Norman, and C. W. Wolfe. 1997b. Estimation of (co)variance components for Jersey type traits using a repeatability model. J. Dairy Sci. 80:18011806.

Koots, K. R., K. M. Wade, B. W. Kennedy, J. C. M. Dekkers, G. C. Smith, and E. B. Burnside. 1994. Method and effect of adjustment for heterogeneous variance of Holstein conformation traits. J. Dairy Sci. 77:294-302.

Meuwissen, T. H. E., G. de Jong, and B. Engel. 1996. Joint estimation of breeding values and heterogeneous variances of large data files. J. Dairy Sci. 79:310-316.

Miglior, F., P. G. Sullivan, and B. J. Van Doormaal. 2002. Preliminary analysis of Mendelian sampling terms for genetic evaluation validation. Interbull Bull. 27:183-187.

Misztal, I., K. Weigel, and T. J. Lawlor. 1995. Approximation of estimates of (co)variance components with multiple trait restricted maximum likelihood by multiple diagonalization for more than one random effect. J. Dairy Sci. 78:1862-1872.

Reverter, A., B. L. Golden, and R. M. Bourdon. 1994. Method R variance components procedure: Application on the simple breeding value model. J. Anim. Sci. 72:2247-2253.

Weigel, K. A., and T. J. Lawlor. 1994. Adjustment of heterogeneous variance in genetic evaluations for conformation of United States Holsteins. J. Dairy Sci. 77:1691-1701. 